\title{
Heat Transfer in Minichannel Gaseous Cooling*
}

\author{
Kazuo HARA**, Masahiro INOUE*** and Masato FURUKAWA** \\ **Kyushu University \\ 744 Motooka, Nishi-ku Fukuoka, Japan \\ E-mail hara@kyushu-u.ac.jp \\ ${ }^{* * *}$ Sasebo National College of Technology \\ 1-1 Okishinchou, Sasebo Japan
}

\begin{abstract}
Heat transfer was investigated experimentally for high pressure ratio air flow in square minichannels, which were machined on the oxygen free copper block. The sizes of the channels were $0.3,0.6,1.0$ and $2.0 \mathrm{~mm}$, and the length were $10,20,50$ and $100 \mathrm{~mm}$. The pressure ratio was changed widely up to the flow choked at the exit. It was found that the heat transfer coefficient was about 7.3 times greater than fully developed turbulent pipe flow. Experimental result showed that 75 percent of the total heat was transfered in 10 percent inlet portion of the channel.
\end{abstract}

Key words: Minichannel, Heat Transfer, Compressible Flow, Heat Transfer Enhancement

\section{Introduction}

It has been long time since micro or minichannel air flow was proposed to be applicable for direct cooling of electronic devises ${ }^{(1)}$. A high inlet pressure, however, is generally needed to get sufficient flow rate of the cooling air since the flow rate of compressible fluid is approximately proportional to the inlet pressure. A COP (coefficient of performance), the ratio of removed heat and compression energy, tends to deteriorate as the pressure ratio increases. An air flow of high-pressure ratio has not generally been used for cooling applications.

The heat released from CPU increases every year so that the surface heat flux of the micro-tip closes the burnout heat flux of water ${ }^{(2)}$. The cooling method of low thermal resistance is highly looked for because the working temperature of the CPU is not so higher than environment temperature.

The paper describes about the experimental result of heat exchanger adopting the high speed air flow through minichannels, the size of which were $0.3 \mathrm{~mm}$ to $2 \mathrm{~mm}$, and the length were $10 \mathrm{~mm}$ to $100 \mathrm{~mm}$. The pressure ratios of the inlet and outlet were ranged to about 3. The heat transfer coefficient of the short channel attained 7.3 times higher than that of turbulent pipe flow. The result shows a possibility of new cooling devise of air flow, although the heat transfer performance does not exceed the performance of water which is said to be more than fifty times greater than air flow heat transfer.

\section{Nomenclature}
$A$ : channel cross-sectional area
$C_{\mathrm{d}}$ : flow coefficient
$C_{\mathrm{p}}$ : specific heat at constant pressure
$D_{\mathrm{h}}$ : hydraulic diameter of the channel
$h_{\mathrm{m}}$ : mean heat transfer coefficient 
$L$ : channel length

$m$ : mass flow rate of air per channel

$N_{\mathrm{u}}$ : Nusselt number

$P$ : total pressure of the plenum

$P_{\mathrm{r}}$ : Prandtl number

$Q$ : heat transferred through a channel

$R$ : gas constant

$R_{\mathrm{e}}$ : Reynolds number

$S$ : side surface area of the channel

$S_{\mathrm{t}}$ : Stanton number

$T$ : total temperature of the plenum

$T_{\mathrm{w}}$ : wall temperature

$W$ : adiabatic compression work

\section{Greece}

$\theta$. dimensionless temperature $=\left(T_{2}-T_{1}\right) /\left(T_{\mathrm{w}}-T_{1}\right)$

$\lambda$ : thermal conductivity of air

$\rho$ : density of air

$\mu$ : viscosity of air

$\kappa$. specific heat ratio of air

\section{Subscript}

1: upstream plenum

2: downstream plenum

\section{Experimental apparatus and method}

Figure 1 is a schematic of heat transfer equipment, which was composed of, from the bottom, a steel base plate, an electronic heater, two plates of oxygen free copper, Teflon insulator plate and a steel cover plate. Figure 2 (a) is an upper plate with oval shape plenums, the distance between them was regarded as a length $L$ of the test channel. Minichannels of square cross-section were machined on the oxygen free copper block shown in Figure 2 (b) with O-ring groove to prevent air leakage. They were stacked and pressed tightly to compose the heat transfer elements. Four sets of upper plates and lower plates were combined to make 16 test geometries. Table 1 is a combination of width and length of the channels investigated.

The exposed surface of the upstream plenum in the upper plate was thermally insulated

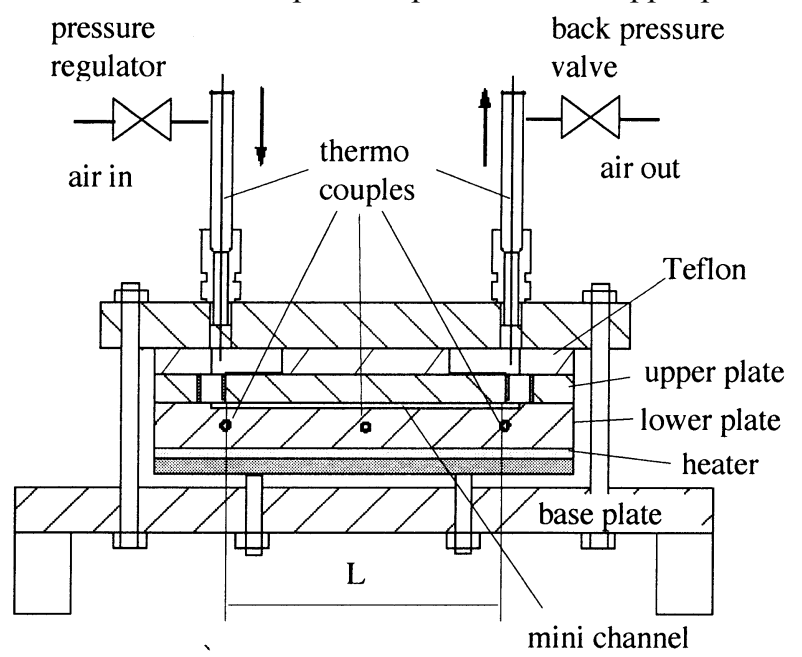

Figure 1 Cross-section of the heat transfer element. 
by urethane foam sheet, however, lower plate was not insulated to perform an inlet part of the minichannel. Downstream plenum was also insulated in the same way as upstream plenum. Thermocouples were inserted in an inlet tube and an outlet tube with glass wool sheath to prevent heat conduction from the tube.

An electronic controller regulated wall temperature to keep center of lower plate at $70^{\circ} \mathrm{C}$. Air was supplied from a compressor through a dryer, a pressure regulator and a mass flow meter. Wall temperatures were measured at three points in the lower plate as shown in Figure 1. An assumption of constant wall temperature was almost satisfied, since typical temperatures were $68.2^{\circ} \mathrm{C}, 70^{\circ} \mathrm{C}$ and $69.3^{\circ} \mathrm{C}$ at upstream, center and downstream positions of lower plate, respectively.

The rate of heat transfer was determined from temperature difference between downstream and upstream plenum and mass flow rate. The mean heat transfer coefficient was estimated with assuming constant heat transfer coefficient distribution and constant wall temperature,

$$
h_{m}=\frac{m C_{p}}{S} \ln \left(\frac{T_{2}-T_{1}}{T_{w}-T_{1}}\right)
$$

with logarithmic temperature difference,

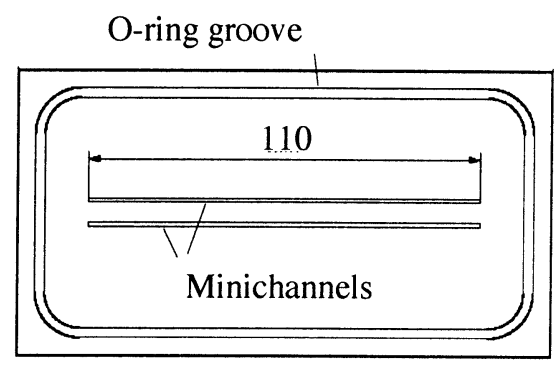

(a) lower plate and minichannel

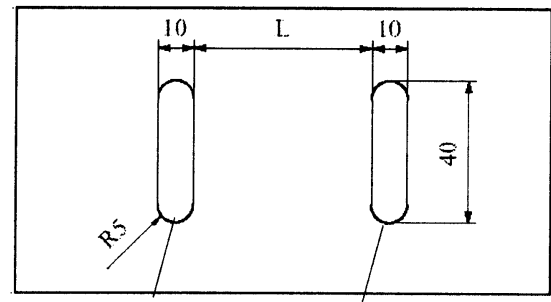

upstream and downstream plenum

(b) upper plate and plenum

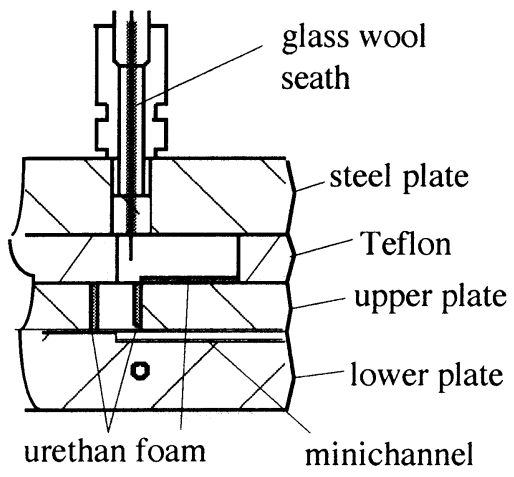

Figure 3 Heat insulator of the plenum

Figure 2 Details of upper and lower plates

\begin{tabular}{|c|c|c|c|}
\hline $\mathrm{Dh}(\mathrm{mm})$ & $\begin{array}{l}\text { Number of } \\
\text { channels }\end{array}$ & $\mathrm{L}(\mathrm{mm})$ & $\mathrm{Tw}\left({ }^{\circ} \mathrm{C}\right)$ \\
\hline $0.3 \times 0.3$ & 10 & $10,20,50,100$ & 70 \\
\hline $0.6 \times 0.6$ & 6 & $10,20,50,100$ & 70 \\
\hline $1.0 \times 1.0$ & 2 & $10,20,50,100$ & 70 \\
\hline $2.0 \times 2.0$ & 1 & $10,20,50,100$ & 70 \\
\hline
\end{tabular}

Table 1 Experimental conditions 


$$
\Delta T=\frac{T_{2}-T_{1}}{\ln \left[\left(T_{w}-T_{1}\right) /\left(T_{w}-T_{2}\right)\right]}
$$

Equation (1) was normalized to get Nusselt number.

$$
N_{u}=\frac{h_{m} D_{h}}{\lambda}
$$

Reynolds number was defined by mean cross-sectional velocity of the channel, which was modified to Equation (4).

$$
R_{e}=\frac{m D_{h}}{\mu A}
$$

In this paper, heat transfer coefficient was also normalized by heat flux of the mean flow per temperature of $1^{\circ} \mathrm{C}$ to get Stanton number by Equation (4), which corresponds to the half of Darcy friction factor of the pipe flow if the Reynold's analogy of the heat transfer is realized.

$$
S_{t}=\frac{h}{C_{p}(m / A)}
$$

Fluid properties were defined at mean temperature of the upstream and downstream plenum.

In order to specify the channel configuration, a notation of $\left(D_{\mathrm{h}}, L\right)$ is used for the channel of width or diameter $D_{\mathrm{h}}$ and length $L$.

\section{Results and discussions}

\subsection{Fundamental characteristics of flow rate and heat transfer}

The fundamental characteristics of heat transfer are shown in Figure 4(a), in which the mass flow rate and heat transfer rate are plotted on pressure ratio. Two results of $(0.3,100)$ channel are selected to show the heat transfer dependency on flow control methods. First way of flow control was done by keeping constant upstream pressure to $0.57 \mathrm{MPa}$ and

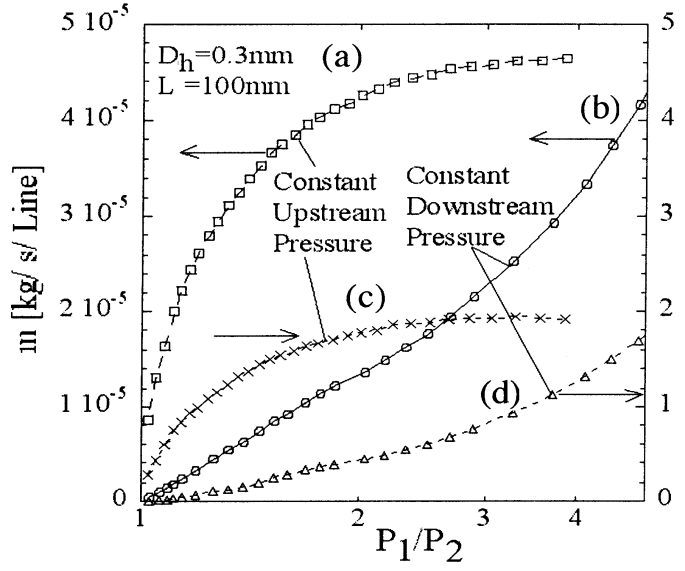

(a) Flow rate and heat transfer rate with pressure ratio

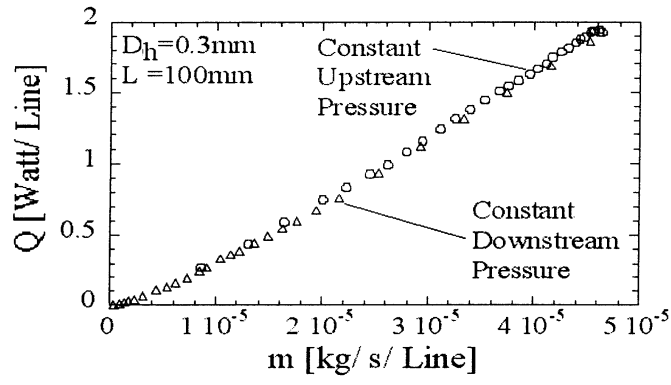

(b) Relation of heat transfer rate and flow rate

Figure 4 Basic flow and heat transfer characteristics for constant inlet pressure and constant outlet pressure 
varying downstream pressure by means of the back pressure valve. Second way was increasing upstream pressure with the back pressure valve fully opened so as to keep downstream pressure atmospheric. The plots of $P_{1}=0.57 \mathrm{MPa}$ show that flow choked in the channel, since plots of flow rate, assigned by (a), kept constant for pressure ratio variation. It was found that in a long and narrow channel of $(0.3,100)$, choking did not affect the heat transfer, since the pressure and density in the channel were not affected by the downstream pressure variation.

Figure 4(b) shows the quantity of heat transferred for each control methods. For $(0.3$, 100) channel, the transferred heat was almost proportional to mass flow rate of the air.

This paper mainly reports the result of changing upstream pressure with back pressure valve fully opened, because the compression work of air increases as the increment of compression pressure.

\subsection{Result of heat transfer}

Figure 5 shows a relation of Nusselt number and Reynolds number. A well known correlation of Dittus-Boelter correlation for fully developed turbulent pipe flow;

$$
N_{u}=0.023 R_{e}^{0.8} P_{r}^{0.4}
$$

and the result of microchannel heat transfer (Wu et al. 1984) are plotted for comparison.

Nusselt number was distributed widely around the Dittus-Boelter correlation, showing great dependency of the heat transfer on the geometries of the minichannel. Nusselt number was found to be 7.3 times greater than Dittus-Boelter correlation especially for (2, 10) channel. The channel of Wu et. al. had a hydraulic diameter of $0.157 \mathrm{~mm}$ from a width of $0.548 \mathrm{~mm}$ and height of $0.092 \mathrm{~mm}$. The $L / D_{\mathrm{h}}$ ratio was 178 from the channel length of $28 \mathrm{~mm}$. The result of $(0.3,50)$ showed somewhat small value.

Flow coefficient was defined by isentropic flow rate of the convergent nozzle $m_{\mathrm{is}}$.

$$
C_{d}=\frac{m}{m_{i s}}
$$

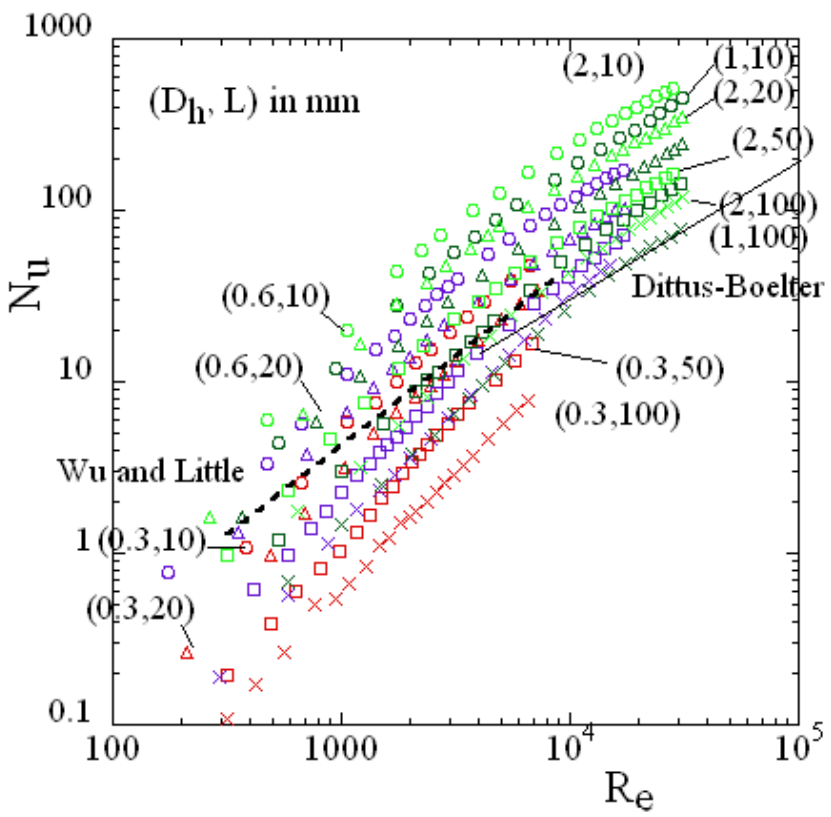

Figure 5 Variation of Nusselt number with Reynolds number 
, where $m_{\text {is }}$ is given by,

For $\frac{P_{2}}{P_{1}} \leq\left(\frac{2}{\kappa+1}\right)^{\frac{\kappa}{\kappa-1}}$

$$
m_{i s}=A P_{1} \sqrt{\frac{\kappa}{R T_{1}}}\left(\frac{2}{\kappa+1}\right)^{\frac{\kappa+1}{2(\kappa-1)}}
$$

For $\frac{P_{2}}{P_{1}}>\left(\frac{2}{\kappa+1}\right)^{\frac{\kappa}{\kappa-1}}$

$$
m_{i s}=A \frac{P_{1}}{\sqrt{R T_{1}}} \sqrt{\frac{2 \kappa}{\kappa-1}\left\{\left(\frac{P_{2}}{P_{1}}\right)^{\frac{2}{\kappa}}-\left(\frac{P_{2}}{P_{1}}\right)^{\frac{\kappa+1}{\kappa}}\right.}
$$

Flow coefficient is shown in Figure 6. One can design a heat exchanger by estimating the flow rate from the figure after specifying the operating pressure ratio. Mean heat transfer coefficient is found from Fig. 5 by calculating a Reynolds number.

COP, coefficient of power, is one of the important index of the heat exchanger and was defined by the ratio of heat transfer rate and adiabatic compression work of the cooling air.

$$
C O P=m C_{p}\left(T_{2}-T_{1}\right) / W
$$

where $W$ is,

$$
W=m \frac{P_{2}}{\rho_{2}} \frac{\kappa}{\kappa-1}\left\{\left(\frac{P_{1}}{P_{2}}\right)^{\frac{\kappa-1}{\kappa}}-1\right\}
$$

The adiabatic efficiency was assumed to be unity and the compression work did not include pumping power of coolant to cool the compressed air to the inlet temperature $T_{1} . \rho_{2}$ is a density of air for $P_{2}$ and $T_{1}$ of the system. Operating pressure ratio should be limited to moderate value, because COP deteriorated rapidly with increasing pressure ratio as shown in Fig. 7.

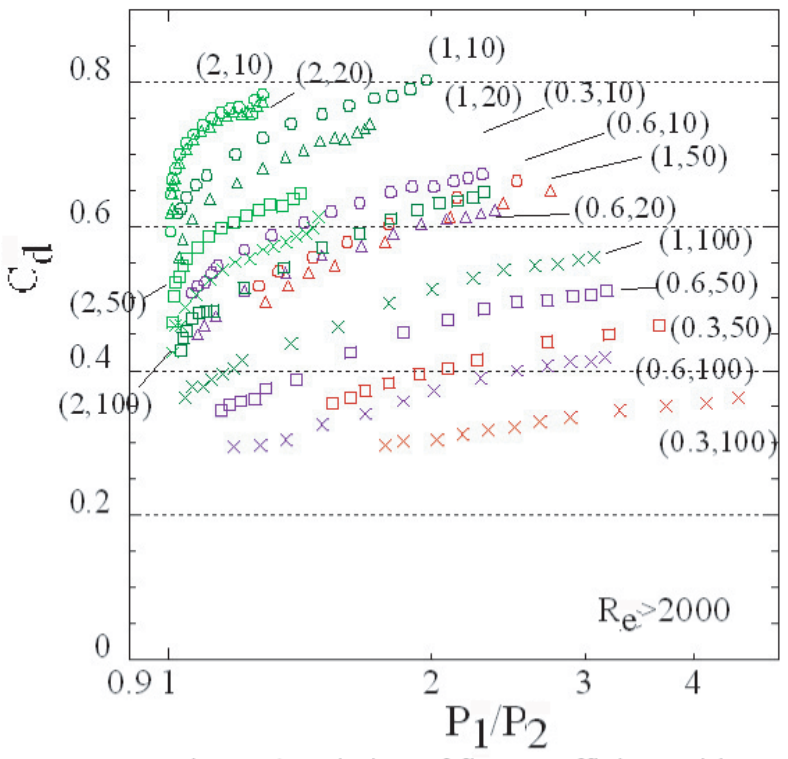

Figure 6 Variation of flow coefficient with pressure ratio 


\subsection{Characteristics of minichannel heat transfer}

Figure 8 shows relations of Stanton number and Reynolds number, in which Dittus-Boetler equation was converted via $S_{\mathrm{t}}=N_{\mathrm{u}} / R_{\mathrm{e}} P_{\mathrm{r}}$ relation. Stanton number is more appropriate than Nusselt number to represent the relationship of heat transfer coefficient to the geometry of heat exchanger, because of little Reynolds number dependency. Utilizing this characteristics, the variation of Stanton number with $L / D_{\mathrm{h}}$ is presented in Fig. 9 for fully developed turbulent region of $R \mathrm{e}>4,000$. The band of Stanton number for Dittus-Boetler equation is also plotted in the figure. Stanton number was found to be greatly affected by length to width ratio, $L / D_{\mathrm{h}}$ of the channel. Some heat transfer enhancement effects were implied to exist from large Stanton number values for small $L / D_{\mathrm{h}}$.

Figure 10 shows a relation of $L / D_{\mathrm{h}}$ and dimensionless temperatures for turbulent region. Although large Stanton number was obtained for small $L / D_{\mathrm{h}}$ in Fig. 9, dimensionless temperature deteriorated for 0.5 or less implying the insufficient heating of air. Approximate

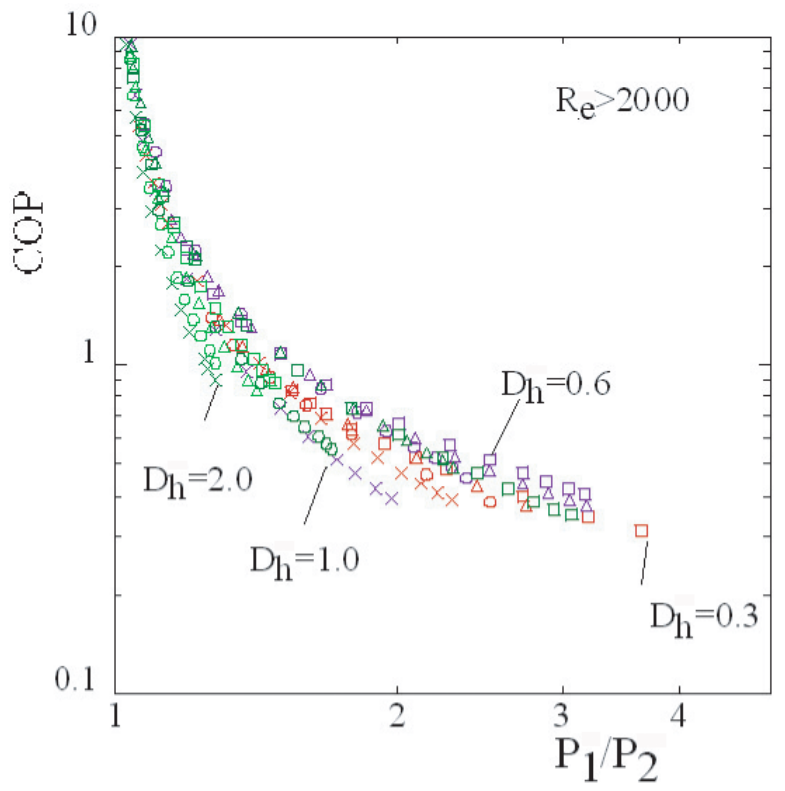

Figure 7 Variation of COP with pressure ratio. Specification of channel configurations are incomplete, because of data over lap.

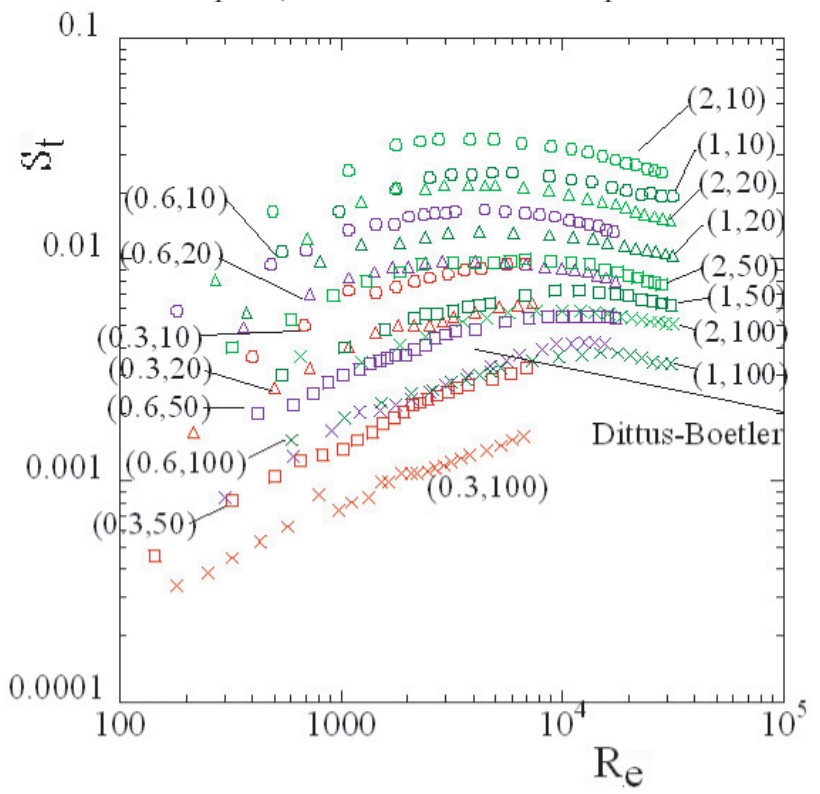

Figure 8 Variation of Stanton number with Reynolds number 
cooling capacity can be easily estimated by calculating flow rate utilizing flow coefficient in Fig. 6, since the dimensionless temperature was mainly a function of $L / D_{\mathrm{h}}$.

Axial distribution of dimensionless temperature was investigated in the same way to the tube cutting method ( $\mathrm{Du}$ et. al. ${ }^{4}$ ) for $D_{\mathrm{h}}=1.0 \mathrm{~mm}$ channel. The procedure of the experiment was as follows. Mass flow rate and downstream temperature were measured first for $L=100 \mathrm{~mm}$ channel with fully opening the back pressure valve for upstream pressure of $0.3 \mathrm{MPa}$ and wall temperature of 70 degree. Then the $L=50 \mathrm{~mm}$ channel was set and operated for the same inlet pressure and wall temperature. The downstream pressure was increased by the back pressure valve so as to get the same flow rate. The temperature of downstream plenum was measured after getting stable condition. This operation was also applied to $L=20 \mathrm{~mm}$ and $L=10 \mathrm{~mm}$ channels. The result of dimensionless temperature distributions were plotted with $L$ in Figure 11.

A calculated dimensionless temperature is also plotted in the figure for same exit dimensionless temperature to the experiment assuming constant heat transfer coefficient

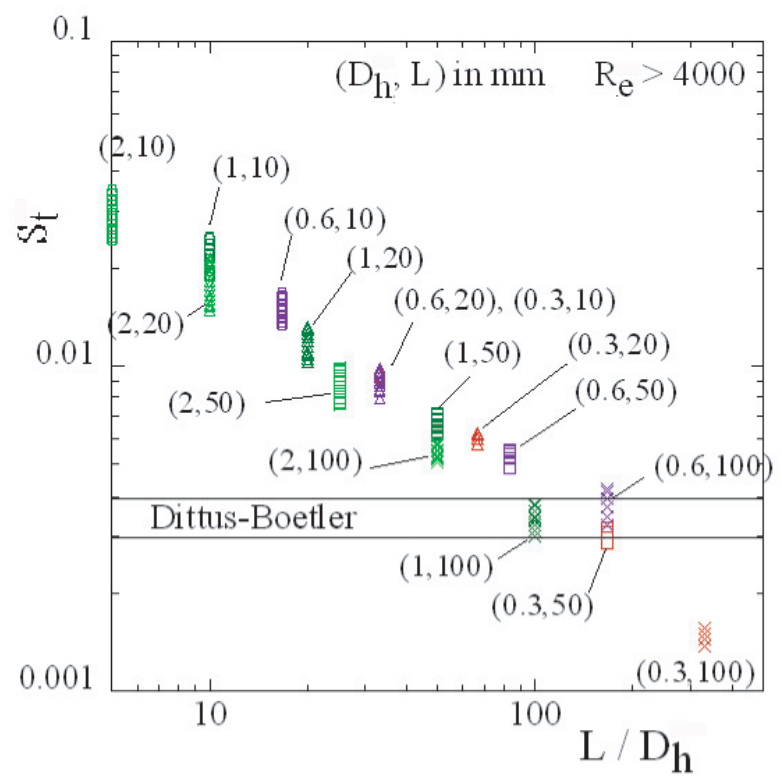

Figure 9 Stanton number with length to width ratio of the minichannel

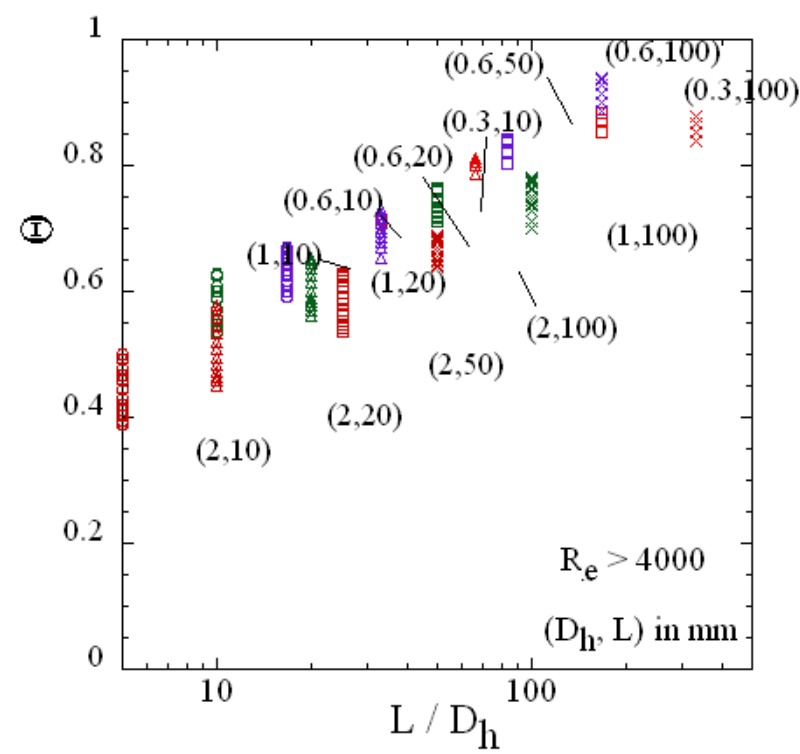

Figure 10 Dimensionless temperature with length to width ratio of the minichannel 
distribution in axial direction. It was found that heat transfer was very large at the channel inlet from the fact that dimensionless temperature was already high there. Almost 75 percent of total heat transfer has been completed up to 10 percent from the channel inlet. The remaining channel was regarded as only a simple friction channel.

\subsection{On the high heat transfer coefficient}

The result showed high Stanton number for small $L / D_{\mathrm{h}}$ ratio in turbulent flow regime compared to the Dittus-Boelter correlation in Figure 8 and 9. Local heat transfer coefficient generally increases two times greater than mean value due to the entrance effect in the inlet region of the channel ${ }^{(6)}$. The effect, however, is diminished when the coefficient is integrated to get mean values for the whole channel. The effect can not explain the high heat transfer coefficient. The CFD result for laminar flow ${ }^{(7)}$ showed high heat transfer region locally when the flow choked at the exit of the channel. These effects also did not explain the experimental result of high heat transfer.

The result of the tube cutting method suggested the importance of heat transfer at the upstream region of the channel. More research is needed to clarify the cause of high heat transfer. It is said that the heat transfer coefficient of water has generally 50 times greater than that of the air. The result of this paper suggested the realization of compact heat exchanger though it is impossible to approach the performance of water cooled heat exchanger.

\section{Conclusions}

The heat transfer and flow characteristics of minichannel have been reported. The size of the channel was 0.3 to $2.0 \mathrm{~mm}$ and the length was $10 \mathrm{~mm}$ to $100 \mathrm{~mm}$. The pressure ratio of upstream and downstream plenum was covered so large that the flow choked at the exit.

Mean heat transfer coefficient was found to be 7.3 times greater than Dittus-Boetler fully developed turbulent flow for small $L / D_{\mathrm{h}}$ ratio of $D_{\mathrm{h}}=2 \mathrm{~mm}$ and $L=10 \mathrm{~mm}$.

It was found that almost 75 percent of heat transfer has been completed by 10 percent from the channel inlet when the dimensionless temperature distribution was investigated after the tube cutting method.

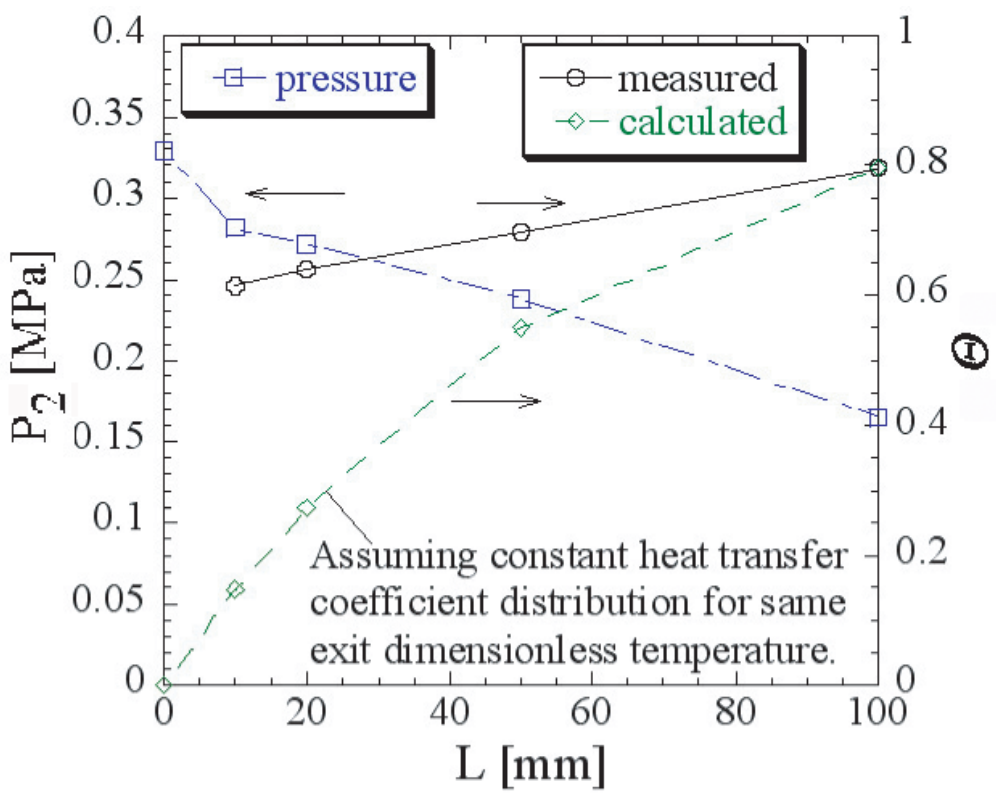

Figure 11 Dimensionless temperature distribution along the channel 


\section{References}

(1)Harley JC, Huang YF, Bau HH, Zemel JN, 1995, 'Gas Flow in Micro Channels', J. Fluid Mech. vol. 284 p. 257-274

(2)Nishio, S., 2001, 'An Overview of Micro Thermal Systems', Proceedings of the TED-COF. 01', JSME, in Japanese

(3) Bird, R. B., Stewart, W. E., Lightfoot, W. N., 'Transport Phenomena', Second

(4) Wu, Peiyi and Little, W. A., 1984, 'Measurement of the heat transfer characteristics of gas flow in fine channel heat exchangers used for microminiature refrigerators', Cryogenics,p. 415

(5) Du DX, Li ZX, Guo ZY, 2000, 'Friction resistance for gas flow in smooth microtubes', SCIENCE IN CHINA SERIES E-TECHNOLOGICAL SCIENCES, 43 (2): 171-177

(6) Archive for Heat Transfer, 1986, Maruzen

(7) Guo. Z. Y., and Wu, X. B., 1997 'Compressibility effect on the gas flow and heat transfer in a microtube', International Journal of Heat and Mass Transfer vol. 40, p. 3251 